\title{
Thoracic esophageal perforation by the use of Magill forceps in infant, success with non-operative treatment: case report
}

\author{
Abdel-Kémal Bori Bata ${ }^{1 *} \mathbb{D}$, Antoine Séraphin Gbénou', Joseph Akodjènou², Aboudou Raïmi Kpossou ${ }^{3}$ \\ Bruno Noukpozoukou ${ }^{1}$ and Armand Michel Fiogbe ${ }^{4}$
}

\begin{abstract}
Background: Esophageal perforation is a rare surgical pathology in children. Thoracic esophageal perforation is more severe than cervical esophageal perforation. latrogenic cause, mainly by endoscopy, is the most common in esophageal perforation. However, perforation induced by "Magill forceps" is exceptional.

Case presentation: A systematic physical examination revealed pyrexia severe respiratory distress and right-sided pleural effusion.

We report the success of non-operative treatment applied to thoracic esophageal perforation due to Magill forceps in a 24-month-old male infant. The immediate and short-term outcomes were excellent.

Conclusions: Non-operative treatment is possible in iatrogenic perforation of thoracic esophageal in infants. This treatment delivers excellent outcome in carefully selected patients.
\end{abstract}

Keywords: Thoracic esophageal, Perforation, Magill forceps, Non-operative treatment

\section{Background}

Esophageal perforation is a rare and severe surgical pathology, with significant morbidity and mortality (10$47 \%)$. The iatrogenic causes are the most common in children. Cervical esophageal perforation is less severe than thoracic esophageal, whose mortality can reach up to $40 \%$ [1-3]. The latter may be complicated with the development of mediastinitis and pleuritis (presentation initially chemical which later becomes infectious) resulting in the onset of a rapidly life-threatening sepsis. Early diagnosis and management are crucial. Although some therapeutic controversies remain, a non-operative treatment responds to a well-codified algorithm $[4,5]$. We report the success of a non-operative treatment applied to thoracic esophageal perforation induced by Magill forceps in an infant.

\footnotetext{
* Correspondence: homelag@gmail.com; bbak@live.fr

${ }^{1}$ Pediatric Surgery Department of Hospital University Center Mother and

Child-Lagune (CHU-MEL), 01 PO Box 107, Cotonou, Benin

Full list of author information is available at the end of the article
}

\section{Case presentation}

AS, a 24-month-old male infant, was admitted to our pediatric surgical emergency unit with a severe respiratory distress associated with high fever and chills. He presented these symptoms $4 \mathrm{~h}$ after an unsuccessful attempt to extract a coin (50 CFA francs) that was accidentally ingested, as identified on the anterior chest $\mathrm{X}$ ray (Fig. 1). An attempted oropharyngeal extraction was performed under general anesthesia with an orotracheal intubation using Magill forceps in a peripheral academic hospital by an ENT specialist team, but the infant was discharged despite failure to extract the foreign object. The infant's gestational, medical, and surgical history were otherwise unremarkable.

The time lapse between the esophageal injury and the patient's management was approximately $4 \mathrm{~h}$. The patient weighed $12 \mathrm{~kg}$ with a height of $85 \mathrm{~cm}$. Systematic physical examination revealed pyrexia at $40{ }^{\circ} \mathrm{C}$, tachycardia at 148 beats $/ \mathrm{min}$, severe respiratory distress (respiratory rate at 70 cycles/min, Silverman score of $8 / 10$, 


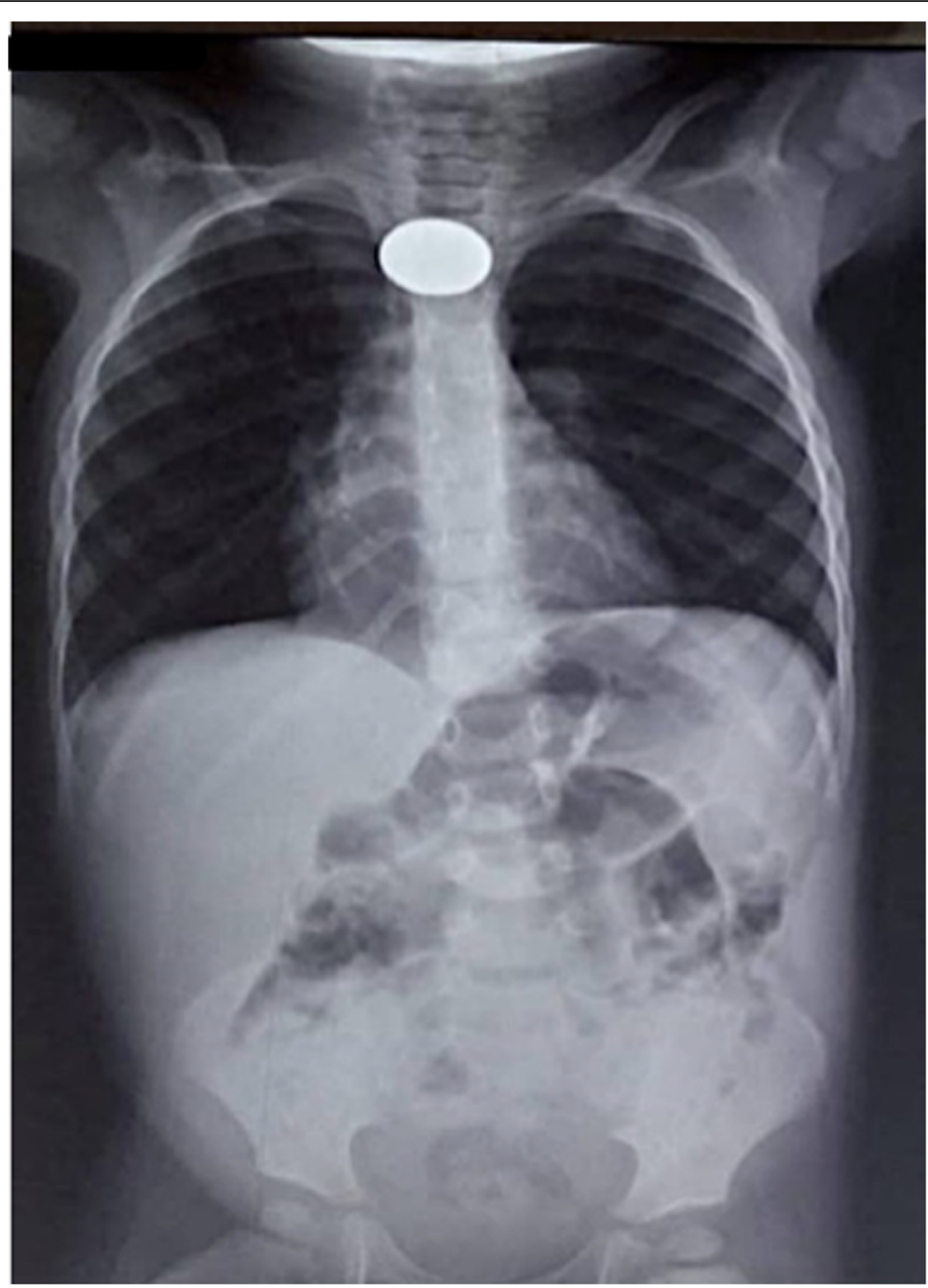

Fig. 1 Chest $X$-ray before attempted instrumental extraction revealing the coin located at the upper third of thoracic esophageal

oxygen desaturation $\mathrm{SpO}_{2} 80 \%$ ), and right-sided pleural effusion syndrome.

Anterior chest X-ray before attempted instrumental extraction revealed the coin located at the upper third of thoracic esophagus (Fig. 1). Chest X-ray at admission in our emergency unit showed right-sided large hydropneumothorax, pneumomediastinum; the coin had continued through the esophageal tract and was located at the level of the stomach (Fig. 2). The esophageal endoscopy revealed $1 \mathrm{~cm}$ of longitudinal ulcerated lesion and a punctiform perforation (less than $5 \mathrm{~mm}$ diameter approximately). The lesions were located $12 \mathrm{~cm}$ from the dental arches on the posterior surface of the thoracic esophagus (union of upper third-middle third) (Fig. 3). Laboratory investigations revealed leukocytosis (10, $\left.000 / \mathrm{mm}^{3}\right)$ with neutrophilia, thrombocytopenia $(139,000 /$ $\left.\mathrm{mm}^{3}\right)$, elevation of C-reactive protein $(96 \mathrm{mg} / \mathrm{L})$, and negative blood culture.
The definite diagnosis was an instrumental perforation of upper third thoracic esophageal grade IV (less than 2$\mathrm{cm}$ disruption of tissue or vasculature) based on the American Association for the Surgery of Trauma (AAST) classification, complicated by a tension hydropneumothorax and acute mediastinitis.

The infant was transferred to a pediatric surgical intensive care unit and we opted for a non-operative management. The latter consisted of oxygen therapy, needle thoracocentesis in the 4th right intercostal space midaxillary line followed by chest tube drainage, avoidance of oral intake, and endoscopic insertion of a nasogastric tube which enabled enteral nutrition. Triple empiric parenteral antibiotics were initiated: amoxicillin/clavulanic acid, metronidazole, and gentamicin. The chest tube was maintained for 7 days and the nasogastric tube for 14 days. The patient was kept NPO for 10 days. 


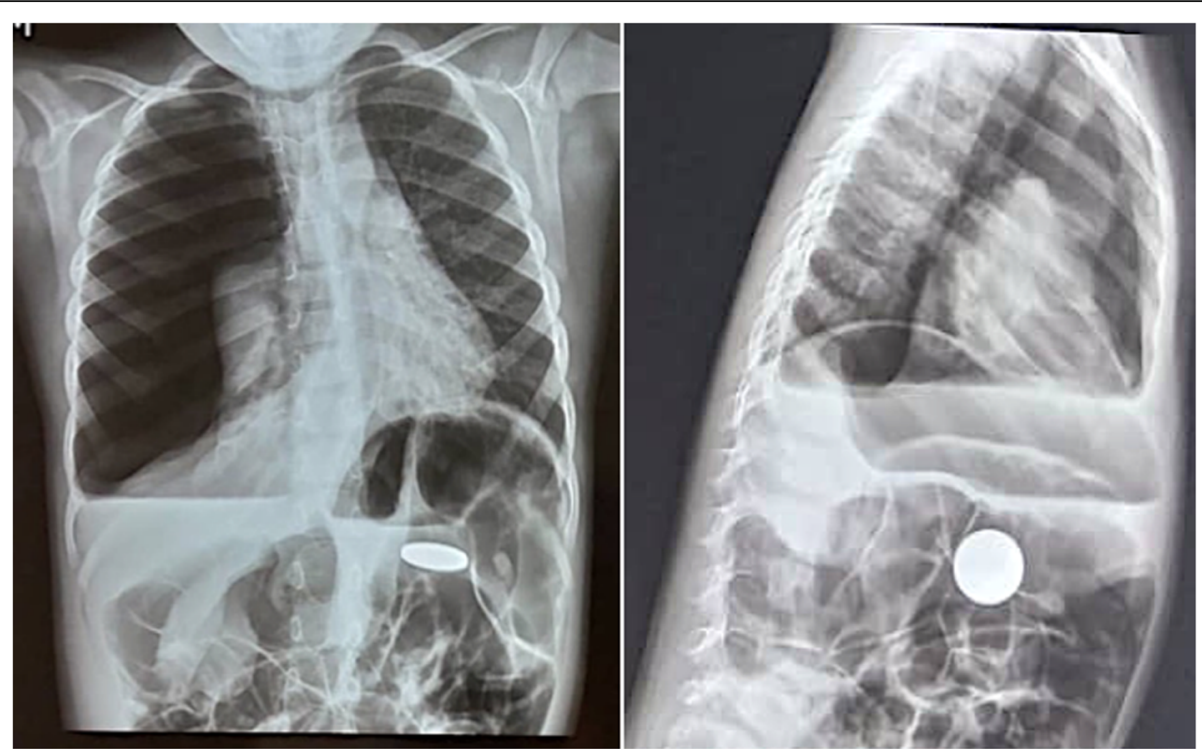

Fig. 2 Admission chest X-ray showing right-sided large hydropneumothorax, pneumomediastinum; the coin located in the stomach

The patient responded progressively with respiratory distress regression, but pyrexia was persistent which led to substitution of amoxicillin/clavulanic acid by imipenem-cilastatin. On day 8 , the infectious syndrome was totally controlled. At the 72nd hour, the coin transited via the digestive tract and was excreted in stool without sequelae. The follow-up chest X-ray revealed complete right-sided lung re-expansion and severe fibrosing pleuritis (Fig. 4). On day 12, a CT scan with esophageal opacification did not reveal any residual perforation or esophago-tracheal fistula. The contrast esophagography performed on day 17 revealed homogeneous opacification without detection of perforation (Fig. 5). Oral intake of food was initiated from the 17th day; the infant was discharged. At a 7-monthfollow-up, he was clinically well with no dysphagia.

\section{Discussion}

Foreign body ingestion is a frequent reason for admission in the pediatric emergency units. It mainly affects small infants ( 3 months to 6 years) with a male predominance [1]. Coins are involved in $70 \%$ of cases; most

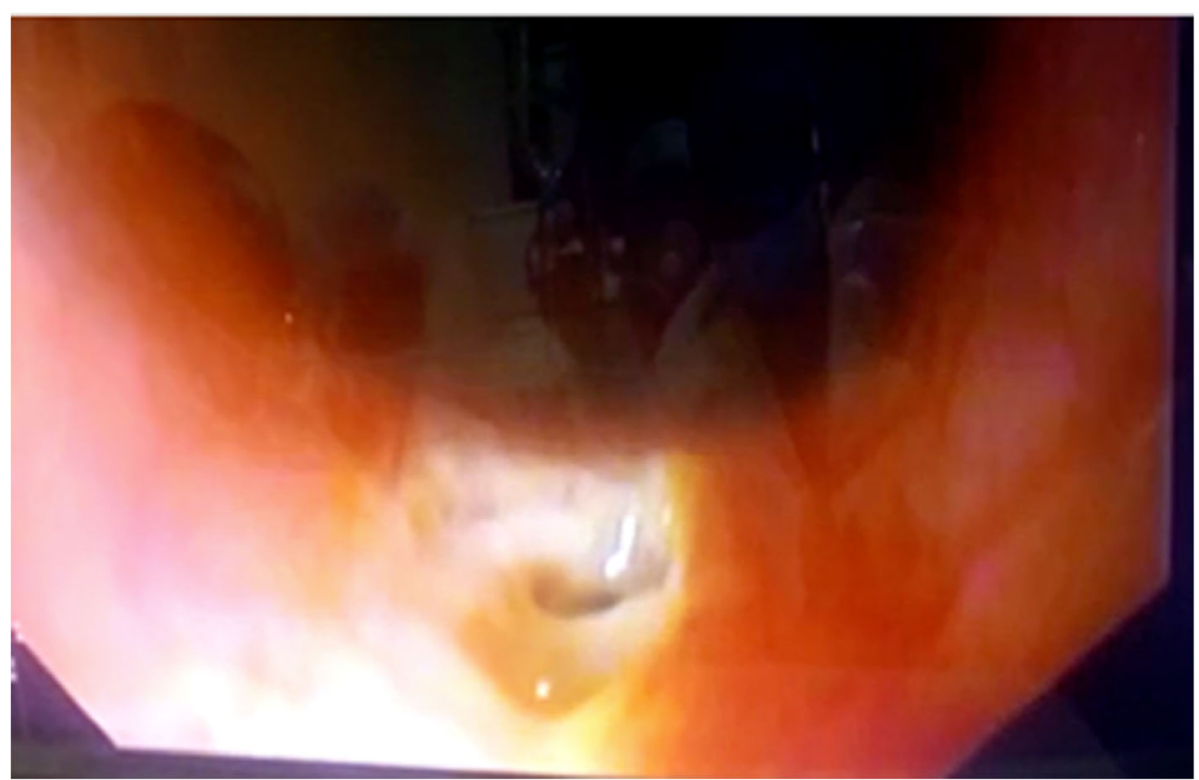

Fig. 3 Endoscopic picture of the thoracic esophageal perforation 


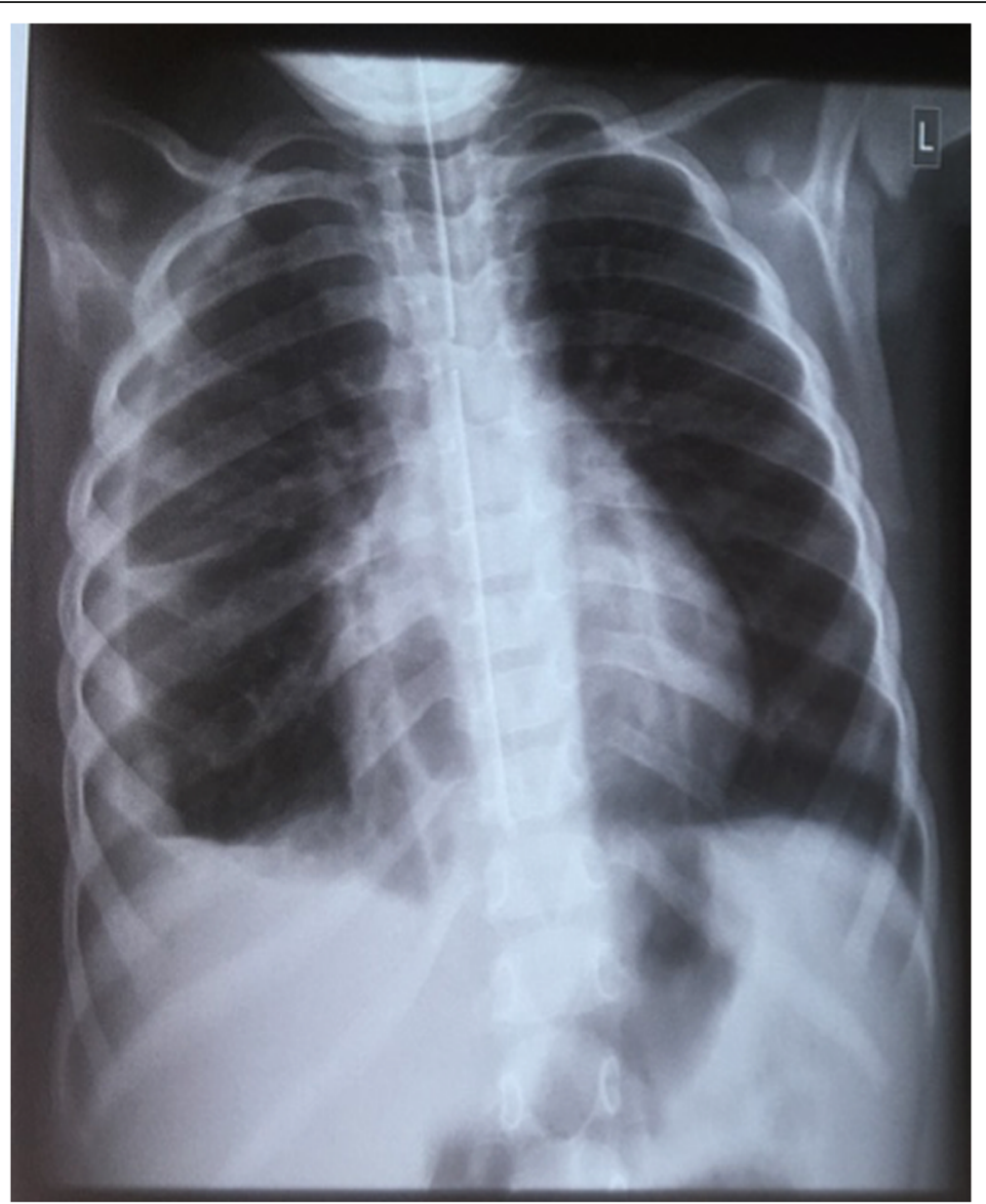

Fig. 4 Chest $X$-ray showing the total re-expansion of the right-sided lung and severe fibrosing pleuritis

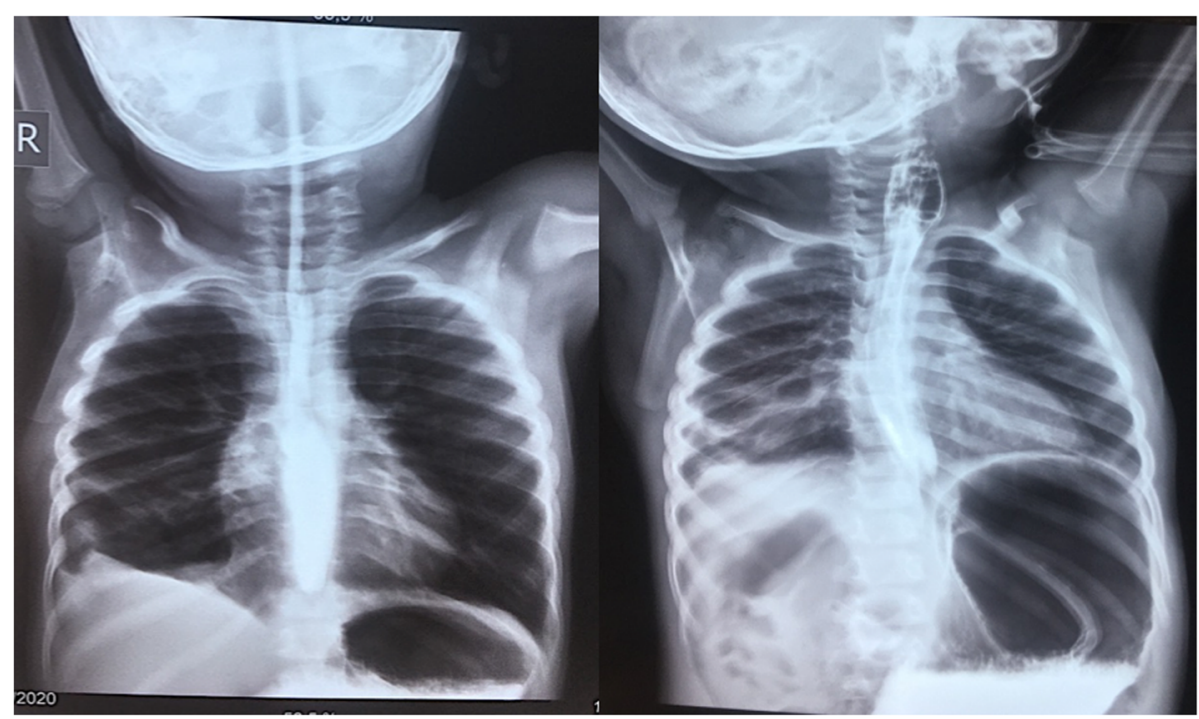

Fig. 5 Contrast esophagography revealed homogeneous opacification without detection of perforation 
foreign bodies transit through the gastrointestinal tract without sequelae and are excreted in the stool [1]. Esophageal perforations are severe in infant; the etiology is mainly iatrogenic (71-84\%), often due to endoscopyrelated procedures.

In our case, given the original site of the coin at the upper third of the thoracic esophageal, the ENT team should not have attempted an instrumental extraction. Unfortunately, the ENT team made a poor management decision at the time. However, a perforation induced by Magill forceps is exceptional $[1,2,6]$. Some ENT teams are used to extract foreign bodies from the cervical esophagus using Magill's forceps with great success and little or no complication [6]. The average of delay diagnosis for esophageal iatrogenic perforations in infants is 1.4 days (0-2 days) [7]. The localization of iatrogenic esophageal perforations is mainly thoracic (75-90\%) whose mortality can reach up to $40 \%[1,8]$. The clinical manifestations of thoracic esophageal perforations are pyrexia (66\%), subcutaneous emphysema (15\%), septic shock (45\%), and respiratory signs (92\%) [3]. The pneumothorax is present in more than $50 \%$ of thoracic perforations; it is often mixed with pleural effusion (hydropneumothorax). The pneumothorax can be combined to right lung lesions in the middle perforation of thoracic esophageal and left lung lesions in distal perforation [3]. The cervicothoracic and abdominal CT scanner with esophageal opacification has emerged as the benchmark diagnostic examination, with a sensitivity close to $100 \%$. The diagnostic role of endoscopy has long been controversial for fear of aggravating the injury. An endoscopy may be helpful in patients who are unable to swallow or if the contrast esophagography is negative. It assesses the possibility of endoscopic treatment and its chances of success [5]. In our case, we opted for an endoscopy with a flexible fiberoptic to confirm the diagnosis and guide the placement of the nasogastric tube. The notion of "conservative management" or "non-operative treatment" has the same connotation. Non-operative treatment includes avoidance of oral intake, endoscopic nasogastric tube insertion, parenteral nutrition support, intravenous broad-spectrum parenteral antibiotics (active on aerobic and anaerobic germs in the ENT sphere), and drainage of any collections. If the patient remains clinically stable, a contrast esophagography should be obtained after 7 days and resumption of oral intake under observation may be considered depending on the results. If the patient demonstrates any evidence of clinical deterioration, with signs and symptoms of infection, surgical intervention is required to control extraluminal contamination and restore continuity of the digestive tract $[2,5]$. In our case, we selected broad-spectrum antibiotics with gram-negative and anaerobic coverage, to prevent systemic infection and progression to sepsis while the perforation heals. In the case of infant AS, in view of the pyrexia, two blood cultures were done but no organisms were isolated. Pleural fluid cultures were unfortunately unavailable. In the absence of cultures and sensitivities to guide antibiotic choice but with the persistence of pyrexia despite triple therapy, we substituted amoxicillin/clavulanic acid by imipenem-cilastatin. This allowed complete control of the infectious syndrome. The first successful non-operative management was described in 1965 with only 1 death in 18 patients treated for instrumental perforation of the thoracic esophagus [2]. The eligibility criteria described by Mengold and Klassen in 1965, modified by Cameron in 1979, by Shaffer in 1992, and by Altorjay in 1997, are intramural perforation and transmural perforation less than $1 \mathrm{~cm}$ with limited paraesophageal extension, a perforation seen early $(24-48 \mathrm{~h})$, a contrast esophagography with the passage of contrast product preferentially into the esophagus not towards the fistula, minimal clinical signs of sepsis and stable hemodynamics, and clinical improvement within $24 \mathrm{~h}$ of starting treatment $[1,2,5]$. Non-operative treatment is appropriate for most iatrogenic perforations in an infant; careful selection of patients has achieved 90-100\% survival rates [1, 7]. It gives similar or even superior results to first-line surgical treatment $[8,9]$.

Some authors recommend conservative management in iatrogenic esophageal perforations in children and apply surgical treatment to contraindication or conservative management failure [9]. In our case, it was a perforation of the upper third thoracic esophagus, seen early (4th hour) in the infant and managed early. The immediate and short-term outcome was excellent. We opted for a non-operative treatment that has less morbidity, due to the size of the perforations less than $15 \mathrm{~mm}$ and the hemodynamic stability of the patient after thoracic drainage. This allowed us to avoid a more aggressive open surgery by thoracotomy in a context where the parents have disadvantaged socioeconomic conditions. Moreover, conservative management avoids the complications and sequelae associated with open surgery.

\section{Conclusion}

Removal of a foreign body with Magill forceps can induce esophageal perforation. Non-operative treatment is possible in iatrogenic perforation of thoracic esophageal in infants. This treatment delivers excellent outcomes in carefully selected patients.

\section{Acknowledgements}

Not applicable.

Authors' contributions

AKBB managed the child, operated, and wrote down the case; ARK managed the procedure of esophageal endoscopy, and JA and BN assisted and 
supervised in operating upon the child; ASG and AMF supervised and did the critical revision. All authors have read and approved the final manuscript.

\section{Funding}

Not applicable.

Availability of data and materials

Available upon request.

\section{Declarations}

Ethics approval and consent to participate

Not applicable.

\section{Consent for publication}

Written informed consent for publication was obtained from patient's mother as the patient was less than 16 years old.

\section{Competing interests}

The authors declare that they have no competing interests.

\section{Author details}

${ }^{1}$ Pediatric Surgery Department of Hospital University Center Mother and Child-Lagune (CHU-MEL), 01 PO Box 107, Cotonou, Benin.

${ }^{2}$ Anesthesia-Resuscitation Unit of Hospital University Center Mother and Child-Lagune (CHU-MEL), 01 PO Box 107, Cotonou, Benin. ${ }^{3}$ Hepatology and Gastroenterology Department of National University Hospital Koutoukou Hubert Maga (CNHU-HKM), Cotonou, Benin. ${ }^{4}$ Pediatric Surgery Department of National University Hospital Koutoukou Hubert Maga (CNHU-HKM), Cotonou, Benin.

Received: 24 March 2021 Accepted: 24 June 2021

Published online: 12 October 2021

\section{References}

1. Govindarajan KK. Esophageal perforation in children: etiology and management, with special reference to endoscopic esophageal perforation. Korean J Pediatr. 2018;61(6):175-9.

2. Lampridis S, Mitsos S, Hayward M, Lawrence D, Panagiotopoulos N. The insidious presentation and challenging management of esophageal perforation following diagnostic and therapeutic interventions. J Thorac Dis. 2020;12(5):2724-34.

3. Schmutz G, Régent D, Diez-Martinez P, Tan S, Hoang ML, Hannequin F, et al. Ruptures et perforations œsophagiennes. EMC - Radiologie et imagerie médicale - abdominale - digestive. 2017;12(3):1-22 [Article 33-090-A-15].

4. Sudarshan M, Cassivi SD. Management of traumatic esophageal injuries. J Thorac Dis. 2019;11(2):172-6.

5. De Moor V, Lemaire J, Rosière A, Michel L. Traitement des perforations œsophagiennes. EMC - Techniques chirurgicales - Appareil digestif. 2018; 13(4):1-13 [Article 40-220].

6. Oncel M, Sunam GS, Elsurer C, Yildiran H. Use of Magill forceps to remove foreign bodies in children. Surg J (N Y). 2017;3(2):e91-5.

7. Garey CL, Laituri CA, Kaye AJ, Ostlie DJ, Snyder CL, Holcomb GW 3rd, et al. Esophageal perforation in children: a review of one institution's experience. J Surg Res. 2010;164(1):13-7.

8. El-Asmar KM, Elghandour MM, Allam AM. latrogenic esophageal perforation caused by endoscopic dilatation of caustic stricture: current management and possibility of esophageal salvage. J Pediatr Surg. 2020;S0022-3468(20): 30370-5.

9. Al Jubab A, Jafarli I, Al Tokhais T. Surgical versus non-surgical treatment for traumatic esophageal perforation in children: a systematic review. Journal Of Current Surgery. 2016;6(2):41-5.

\section{Publisher's Note}

Springer Nature remains neutral with regard to jurisdictional claims in published maps and institutional affiliations.

\section{Submit your manuscript to a SpringerOpen ${ }^{\circ}$ journal and benefit from:}

- Convenient online submission

- Rigorous peer review

- Open access: articles freely available online

High visibility within the field

- Retaining the copyright to your article

Submit your next manuscript at $\boldsymbol{\nabla}$ springeropen.com 